\title{
Using decision trees to predict benthic communities within and near the German Exclusive Economic Zone (EEZ) of the North Sea
}

\author{
Roland Pesch • Hendrik Pehlke • Kerstin Jerosch • \\ Winfried Schröder • Michael Schlüter
}

Received: 24 July 2006 / Accepted: 28 February 2007 / Published online: 7 August 2007

(C) Springer Science + Business Media B.V. 2007

\begin{abstract}
In this article a concept is described in order to predict and map the occurrence of benthic communities within and near the German Exclusive Economic Zone (EEZ) of the North Sea. The approach consists of two work steps: (1) geostatistical analysis of abiotic measurement data and (2) calculation of benthic provinces by means of Classification and Regression Trees (CART) and GIS-techniques. From bottom water measurements on salinity, temperature, silicate and nutrients as well as from punctual data on grain size ranges (0-20, 20-63, 63-2,000 $\mu$ ) raster maps were calculated by use of geostatistical methods. At first the autocorrelation structure was examined and modelled with help of variogram analysis. The resulting variogram models were then used to calculate raster maps by applying ordinary kriging procedures. After intersecting these raster maps with punctual data on eight benthic communities a decision tree was derived to predict
\end{abstract}

R. Pesch $\cdot$ H. Pehlke $\cdot$ W. Schröder

Landscape Ecology, University of Vechta,

Vechta, Germany

K. Jerosch $\cdot$ M. Schlüter

Alfred-Wegener-Institute,

Bremerhaven, Germany

R. Pesch $(\square)$

Institute for Environmental Science, University of Vechta,

Postfach 1553, 49377 Vechta, Germany

e-mail: rpesch@iuw.uni-vechta.de the occurrence of these communities within the study area. Since such a CART tree corresponds to a hierarchically ordered set of decision rules it was applied to the geostatistically estimated raster data to predict benthic habitats within and near the EEZ.

Keywords Benthic habitat mapping $\cdot$ Benthos $\cdot$ North Sea $\cdot$ Exclusive Economic Zone (EEZ) · Multivariate statistics $\cdot$ Classification and Regression Trees $($ CART $) \cdot$ Geostatistics

\section{Background and objectives}

The investigation of the spatial distribution of benthic organisms inhabiting the sediments of the sea floor of the North Sea has a long tradition. First attempts go back to the work of Petersen (1914), who characterised dominant benthic species, relying on bathymetry and sediments. Since then the macrozoobenthos has been investigated in different parts of the North Sea leading to numerous publications (summarised in Glémarec 1973; Kingston and Rachor 1982). With regard to the German Bight the survey carried out by Salzwedel et al. (1985) in October 1975 produced a detailed data set on the macrofaunal communities for the sublitoral. The spatial distribution of these benthic communities was nearly affirmed in an extensive study made by Rachor and Nehmer (2003). Here data on benthic organisms were collected at 182 sites 
within the area of the German Bight and the bordering central North Sea. With help of multivariate statistics the abundance data was aggregated to derive eight benthic communities representative for the biological conditions at the sea floor. These communities also include information on benthic organisms that are referred to as endangered species.

The goal of this article is to calculate a prediction map for the occurrence of these benthic communities for the whole area within and near the German Exclusive Economic Zone (EEZ) of the North Sea. We refer to the resulting prediction map as a benthic habitat map able to describe the biotic and abiotic conditions at the sea floor. According to the ICES (International Council for the Exploration of the Sea) Working Group on Marine Habitat Mapping a marine habitat can be defined as "[a] recognizable space which can be distinguished by its abiotic characteristics and associated biological assemblage, operating at particular spatial and temporal scales." (ICES 2005). The knowledge of such ecological units often is a prerequisite for marine planning and management needs, such as the installation of offshore wind power plants or the declaration of protection zones (Hughes 1997; Reiniger 1997; Lourie and Vincent 2004). In Europe the EUNIS (European Nature Information System) habitat classification system provides a hierarchical concept to characterise habitats in Europe's terrestrial and marine environments. Currently different international research groups focus on the application of the EUNIS concept although encountering problems when trying to adjust existing marine data to the according classification rules. Our habitat mapping concept takes into account availability of marine data by aggregating abiotic and biotic measurements to benthic habitat types with help of statistical methods as well as GIS-technologies. Two methodical work steps can be distinguished:

(1) With aid of geostatistical methods abiotic measurement data on grain size ranges as well as on salinity, nutrients, silicate and temperature for the lower water body are spatially extrapolated to raster maps.

(2) Together with site specific data on benthic organisms the calculated raster maps are used to derive a hierarchical classification system for eight benthic communities derived by Rachor and Nehmer (2003) by means of Classification and Regression Trees (CART). The resulting decision tree is applied to predict the occurrence of these benthic communities for the EEZ.

\section{Materials and methods}

Geostatistical methods

Originally applied to estimate mineral resources and reserves (Krige 1951; Matheron 1965, 1971), nowadays geostatistics are used in marine environmental research, too (Chihi et al. 2000; Jerosch et al. 2006; Petitgas 1997; Poon et al. 2000; Schlüter et al. 1998; Stelzenmüller 2005). In geostatistics the spatial autocorrelation of measured properties is at first examined and then modelled by variogram analysis. Variogram analysis consists of two work steps: calculation of an experimental semivariogram from measurement values and fitting a mathematical variogram model. Variogram maps may be used to examine whether the spatial dependency not only changes with distance but also with direction (Johnston et al. 2001). Variogram models usually are described with respect to three significant measures: nugget-effect, sill and range. The range equals the maximum distance within which a distinct increase of semivariogram values indicates spatial auto-correlation. The sill corresponds to the semivariance assigned to the range. In cases of anisotropies, either the range or the sill (or both) will vary with respect to direction. Small-scale variabilities or measurement errors may lead to high semivariances at nearby locations causing the variogram model to cut the ordinate above the origin (nugget effect). A pure nugget effect indicates a complete lack of spatial auto-correlation.

Based on the variogram model, kriging can be used to make predictions for a defined point raster. Several kriging options (e.g. simple, ordinary or universal kriging) enable minimising the estimation variance and weighted averaging of the measured values within a chosen searching or kriging window. Whether or not anisotropies are detected in the variogram analyses determines whether this kriging window is circular (no anisotropies) or ellipsoidal (different ranges of spatial autocorrelation for different directions).

Cross-validation should be used for fitting an adequate variogram model and for describing the 
equality of estimation. For this purpose, each measurement value is extracted from the dataset and estimated by kriging based on the selected variogram model. By subtracting each measured value from its estimated value an estimation or cross-validation error can be calculated resulting in an error distribution for the whole dataset. Examples of such parameters are: the mean error (ME - the average value of the crossvalidation errors which at best should be 0 ), the root mean square standardised error (RMSSE - ratio of mean squared crossvalidation errors and the kriging variances which at best should equal 1), the Mean Percentile Error (MPE - the median of all absolute values of the cross-validation errors in percent where the measured value is set $100 \%)$, and the correlation coefficient after Spearman $\left(C_{\mathrm{S}}-\right.$ in case of an ideal correlation the $C_{\mathrm{S}}$-value should equal 1 , if no such correlation exists $C_{\mathrm{S}}$ tends towards 0 ).

\section{Classification and regression trees (CART)}

CART is introduced as a statistical procedure to derive a classification system or decision tree, respectively, for the occurrence of benthic communities in the area of the German EEZ of the North Sea. CART is applied in various scientific disciplines to uncover hidden structures in complex data matrices and to predict the characteristics of a chosen target variable by a set of meaningful predictor variables (Breiman et al. 1984). In psychological and medical research, for example, decision trees like the ones calculated with CART are applied to understand and predict human characteristics, behaviours and even diseases (Swan et al. 2004; Arentze and Timmermans 2005; Rosenfeld and Lewis 2005). In environmental sciences application examples can be found in environmental monitoring (Ryan 1995; Schröder and Schmidt 2003), global change biology (Thuiller 2003), applied forestry (Lawrence and Labus 2003) and meteorology (Walmsley et al. 2001). In marine biology Norcross et al. (1999) used CART to classify near shore flatfish habitats in Alaska's waters. Huetmann and Diamond (2001) predicted and modelled the distribution of seabirds in the Canadian North Atlantic by applying CART.

CART handles both categorical and metric data without data transformation and produces decision trees to display class memberships by recursively partitioning a heterogeneous data set into subsets (also called classes, groups, nodes) by means of a series of binary splits. The aim is to create subsets that improve in terms of homogeneity according to the features of the target variable. How each node is split into two subnodes is determined with the help of the predictor variables. Whether the target variable is of metric, ordinal or nominal scale dignity different impurity measures exist. The Gini index is commonly used when the target variable is categorical, although other options exist (entropy, twoing index) (Steinberg and Colla 1995):

$g(a)=1-\sum_{i} P(i / a)^{2}$

In Eq. $1 g(a)$ represents the Gini measure of a given node $a$ and is determined by subtracting the sum of all squared probabilities of all features $i$ of the target variable from 1 . The Gini index becomes 0 if all cases in the node belong to the same category (optimal homogeneity) and reaches its maximum when all cases are evenly distributed within the node. To choose the optimal binary split the maximum reduction of inhomogeneity is calculated over all possible splits by using the following equation (Yisehac and Webb 1999):

$\Delta i(s, t)=i(t)-p_{\mathrm{L}}\left[i\left(t_{\mathrm{L}}\right)\right]-p_{\mathrm{R}}\left[i\left(t_{\mathrm{R}}\right)\right]$

Here $\Delta i(s, t)$ stands for the decrease in impurity or the improvement at a particular split $s$ of node $t$. The terms $p_{\mathrm{L}}$ and $p_{\mathrm{R}}$ are the proportions of the cases at node $t$ that go into the left and right subnode and $I\left(t_{\mathrm{L}}\right)$ and $I\left(t_{\mathrm{R}}\right)$ are the impurities of the left and the right subnode.

Thus, decision trees are processed until a maximum tree is reached depending on user specified restrictions, e.g. insufficient number of cases in a produced node or until further splitting is impossible (only one case or identical cases in the node). Smaller trees can be produced by pruning the maximum tree either automatically or interactively by expert judgement. In this way all decision trees result in so called endnodes which are the product of a hierarchical sequence of decision rules. These may now be applied on objects where information on the predictor variables is given and that on the target variable is missing. By dividing all misclassified cases through the total number of cases a prediction quality measure may be expressed in terms of a misclassification rate or risk estimate. 


\section{Data basis and preparation}

The data set used to predict benthic communities was collected within the framework of the project MarGIS financially supported by the German Federal Ministry of Education and Research. Along with thematic surface data (e.g. sediment data maps) most of these data consist of biotic (e.g. data on benthic organisms) and abiotic measurements of the lower water column. The data sets were provided by several national and international databases and projects and were integrated in a relational Database Management System (rDBMS) (Jerosch et al. 2005). Approximately 235,000 abiotic measurement data sets were collected from the ICES Data Base, the Marine Environmental Data Base (MUDAB) of the German Federal Maritime and Hydrographic Office (BSH) and the German Federal Environmental Agency (UBA) as well as the Institute of Marine Research (IfM), University of Hamburg for the North and the Baltic Sea.

For the calculations performed here data on eight benthic communities derived in summer 2000 by Rachor and Nehmer (2003) (Fig. 1) as well as abiotic measurement data on salinity, temperature, silicate, nitrate, ammonium and on grain size ranges (0-20, 20-63, 63-2,000 $\mu$ ) were taken from the MarGIS database for the study area. The latter was extended to a $40 \mathrm{~km}$ buffer around the EEZ in order to improve the geostatistical estimations for the outer parts of the EEZ. Since the abiotic data were to serve as the predicting variables in the CART analysis, the data were aggregated over a 6 year period from 1995 to 2000 according to four monthly time intervals: January-March; April-June; July-September and October-December. By integrating these data sets in ArcGIS (Version 9.0) the site-specific data were checked with respect to its spatial distribution. Only those datasets were considered for further statistical analyses that covered the whole area of interest. These are summarised in Table 1.

In addition to the abiotic parameters listed in Table 1 an already existing map on bathymetry was included in the calculation of benthic habitats. This map was made available by the Alfred-WegenerInstitute, Bremerhaven.

\section{Geostatistical analysis of abiotic measurement data}

The extension 'Geostatistical Analyst' from ArcGIS 9.0 was used to calculate raster data on bottom water measurements on salinity, temperature, silicate, phosphate and nitrate as well as on grain size ranges $(0-20,20-63,63-2,000 \mu)$. The calculations were performed for a 6 year period from 1995 to 2000 according to the four monthly time intervals
Fig. 1 Benthic communities within the German Bight and bordering Central North Sea (Rachor and Nehmer 2003)

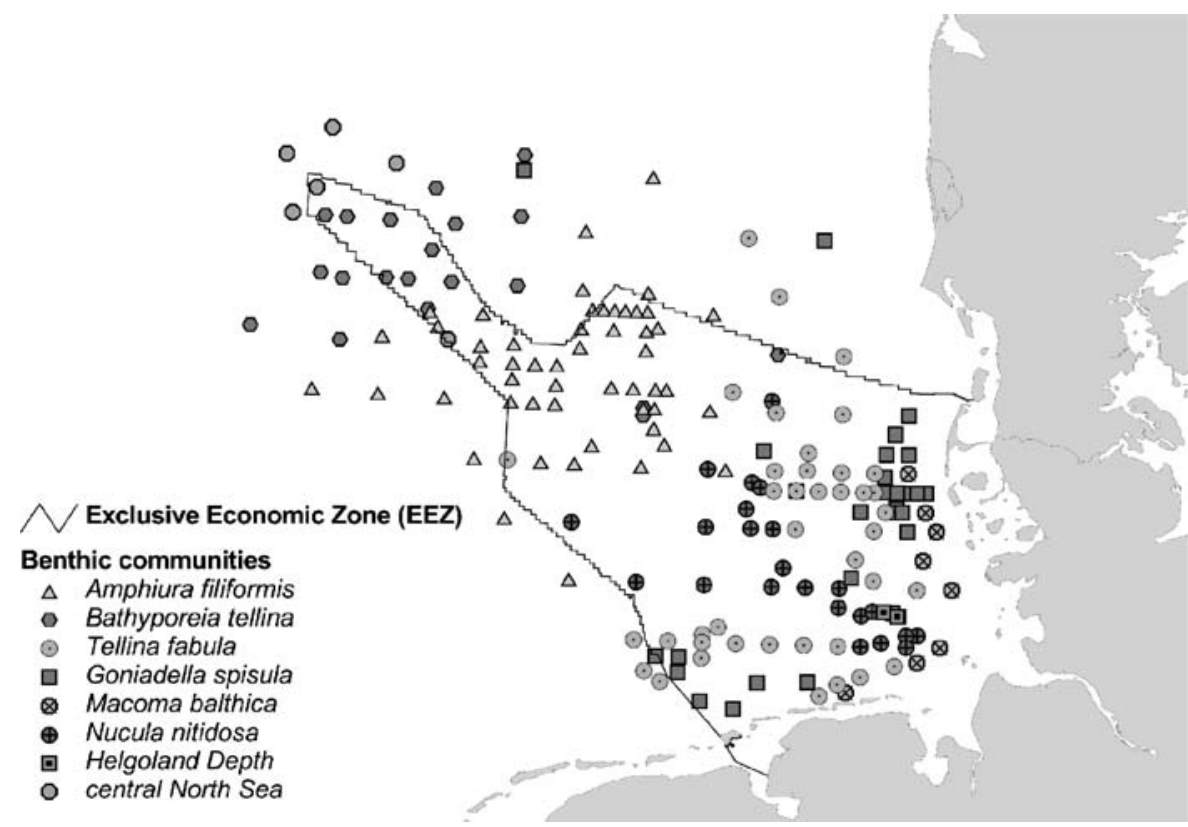


Table 1 Data basis for the prediction of benthic communities within the EEZ plus a $40 \mathrm{~km}$ buffer

\begin{tabular}{llll}
\hline Parameter & Months & Sample size & $\begin{array}{l}\text { Mean nearest neighbor } \\
\text { distance (m) }\end{array}$ \\
\hline Ammonium & January-March & 256 & 4,838 \\
Nitrate & July-September & 197 & 6,638 \\
& January-March & 198 & 6,046 \\
Phosphate & July-September & 239 & 4,076 \\
& January-March & 292 & 4,526 \\
Salinity & July-September & 247 & 4,270 \\
& January-March & 907 & 1,351 \\
April-June & 670 & 2,200 \\
Silicate & July-September & 919 & 2,040 \\
& October-December & 644 & 1,199 \\
Temperature & January-March & 304 & 3,745 \\
& July-September & 223 & 4,993 \\
& January-March & 913 & 1,384 \\
& April-June & 668 & 2,191 \\
grain size range 0-20 & $\mu$ & 921 & 2,030 \\
grain size range 20-63 $\mu$ & 645 & 1,184 \\
grain size range 63-2,000 $\mu$ & 674 & 1,454 \\
\hline & July-September & 662 & 1,451 \\
& October-December & 668 & 1,443 \\
\hline
\end{tabular}

mentioned above. The Universal Transverse Mercator (UTM) coordinate system (Zone 32) was used as a spatial reference system.

According to Webster and Oliver (2000) the mean distance of each measurement site to its nearest neighbour was set as a starting point for the lag size (Table 1). Whether or not the autocorrelation structure could be detected in the variogram window a multitude of this distance was applied. The number of lags allocated to each lag size was set so that the distance of significant autocorrelation (range) became clearly visible in the variogram window. In a next step we tested various variogram models, including different types of models, sills, ranges, and nugget effects. Finally, if the semivariances displayed on the variogram map indicated anisotropies in the data field, different ranges for different directions (to account for anisotropies) were compared with each other. All variogram parameters (range, sill, nugget-effect, type of variogram model, anisotropies) were chosen with respect to the ME, the RMSSE and the RMSE derived from the results of crossvalidation.

The results of variogram analysis depict distinct autocorrelations patterns for all abiotic parameters and time intervals (Table 2). Almost all calculated spherical variogram models show low nugget-sill ratios (n-s-ratio in Table 2), ranging from 0.02 (salinity
[PSU]: April-June) to 0.57 (temperature $\left[{ }^{\circ} \mathrm{C}\right]$ : JanuaryMarch). Ninety percent of the nugget-sill ratios lie below 0.5 which is indicative for low small-scale variances and strong autocorrelations of the measurement values. With the aid of variogram maps anisotropies could furthermore be detected resulting in searching ellipses instead of circles in the succeeding kriging interpolations. The form of these ellipses may be described by means of the anisotropy-ratio (a-ratio in Table 2) which is the proportion of the minor axis of the ellipse to its major axis. A low anisotropy-ratio is therefore equivalent to a narrow searching ellipse resulting in more coastal parallel spatial structures in the kriging maps. The direction of the major axes of the searching ellipses of all 20 parameters mirror different parts of the coastline of the German, Danish and Dutch coastal parts of the study area. They reach from $327.5^{\circ}$ for the salinity conditions from October to December (NNE-direction) to $93.1^{\circ}$ for the temperature conditions in the same time interval (E-direction).

Ordinary kriging was applied to use the information of the variogram model for surface estimations. The grid cell size was set with respect to the average mean distance of neighbouring point pairs over all parameters for all time intervals, here 3,150×3,150 m. The kriging window, which includes the measurement 
Table 2 Key parameters from variogram analysis

\begin{tabular}{llllc}
\hline Dataset & & N-S-ratio & A-ratio & Direction \\
\hline \multirow{2}{*}{ Ammonium } & January-March & 0.29 & 0.59 & 16.7 \\
Nitrate & July-September & 0.31 & 0.61 & 56 \\
\multirow{3}{*}{ Phosphate } & January-March & 0.13 & 0.39 & 0.1 \\
& July-September & 0.48 & 0.43 & 58.2 \\
Salinity & January-March & 0.32 & 0.47 & 356.5 \\
& July-September & 0.23 & 0.53 & 40.2 \\
& January-March & 0.16 & 0.56 & 340.6 \\
Silicate & April-June & 0.02 & 0.73 & 339.4 \\
Temperature & July-September & 0.05 & 0.60 & 356.2 \\
& October-December & 0.25 & 0.65 & 327.5 \\
& January-March & 0.18 & 0.43 & 352.2 \\
& July-September & 0.39 & 0.74 & 40.3 \\
Grain size ranges & January-March & 0.57 & 0.73 & 341.6 \\
& April-June & 0.27 & 0.91 & 16.2 \\
& July-September & 0.19 & 0.61 & 55 \\
& October-December & 0.52 & 0.48 & 93.1 \\
& 0 bis $20 \mu$ & 0.17 & 0.91 & 341.7 \\
& 20 bis $63 \mu$ & 0.22 & 0.73 & 23.4 \\
& 63 bis $2,000 \mu$ & 0.06 & 0.74 & 18.6 \\
\hline
\end{tabular}

values to estimate a certain point, was adjusted to the range of the variogram model. A four-sector neighbourhood was defined to avoid directional bias. A maximum of five points was accounted for in each sector to estimate a certain point.

To assess the quality of the surface estimations key parameters were calculated from the results of crossvalidation. These are summarised in Table 3, in which the ME, RMSSE, MPE as well as the $C_{\mathrm{s}}$ values are listed. Both ME and RMSSE indicate neither underestimation or overestimation and therefore no bias in the surface estimations: ME shows that the average crossvalidation errors equal almost zero in all cases. RMSSE equals almost 1 for all parameters and monthly time intervals indicating that variances calculated from the crossvalidation errors by average
Table 3 Quality of estimation by means of crossvalidation

\begin{tabular}{|c|c|c|c|c|c|}
\hline Dataset & & $\mathrm{ME}$ & RMSSE & MPE & $\mathrm{C}_{\mathrm{s}}$ \\
\hline \multirow[t]{2}{*}{ Ammonium } & January-March & 0.00 & 0.94 & 33.8 & 0.78 \\
\hline & July-September & 0.00 & 1.00 & 31.9 & 0.88 \\
\hline \multirow[t]{2}{*}{ Nitrate } & January-March & 0.00 & 0.98 & 22.7 & 0.67 \\
\hline & July-September & 0.00 & 0.98 & 22.7 & 0.53 \\
\hline \multirow[t]{2}{*}{ Phosphate } & January-March & 0.01 & 1.10 & 31.5 & 0.63 \\
\hline & July-September & 0.00 & 0.99 & 14.7 & 0.74 \\
\hline \multirow[t]{4}{*}{ Salinity } & January-March & 0.00 & 1.05 & 27.4 & 0.77 \\
\hline & April-June & 0.00 & 1.01 & 0.6 & 0.91 \\
\hline & July-September & 0.02 & 1.06 & 0.4 & 0.95 \\
\hline & October-December & 0.00 & 1.02 & 0.2 & 0.97 \\
\hline \multirow[t]{2}{*}{ Silicate } & January-March & -0.03 & 0.98 & 19.3 & 0.87 \\
\hline & July-September & -0.04 & 1.08 & 32.8 & 0.56 \\
\hline \multirow[t]{4}{*}{ Temperature } & January-March & 0.00 & 1.01 & 10.5 & 0.60 \\
\hline & April-June & 0.04 & 1.06 & 9.3 & 0.67 \\
\hline & July-September & 0.01 & 0.98 & 4.5 & 0.93 \\
\hline & October-December & -0.02 & 1.04 & 6.7 & 0.42 \\
\hline \multirow[t]{3}{*}{ Grain size ranges } & 0 bis $20 \mu$ & -0.50 & 0.99 & 30.22 & 0.81 \\
\hline & 20 bis $63 \mu$ & -0.95 & 0.99 & 71.71 & 0.70 \\
\hline & 63 bis $2,000 \mu$ & 1.66 & 1.04 & 1.62 & 0.86 \\
\hline
\end{tabular}


equal the theoretical kriging variances. MPE can be observed to be low for the grain size range 63$2,000 \mu$ as well as for all temperature estimations. With acceptation to the monthly time interval from January to March this also holds true for the salinity estimations. Highest MPE's can be found for the grain size range $20-63 \mu(71.7 \%)$, bottom water ammonium for January to March (33.8\%) as well as silicate for July-September (32.8\%). Except for temperature for October-December all coefficients of correlation after Spearman lie above 0.5 . In $45 \%$ of all cases $C_{\mathrm{s}}$ lies above 0.8 indicating high degrees of associations between the measured and estimated values. $C_{\mathrm{s}}$ is permanently high for bottom water salinity for all monthly time intervals.

\section{Predictive benthic habitat mapping by CART}

Our predictive habitat mapping concept relies on the derivation of CART decision models for the occurrence of benthic communities available at 182 sites within and near the German EEZ (Fig. 1) (Pehlke 2005). The benthic communities were statistically derived by Rachor and Nehmer (2003) from abundance data on benthic faunistic organisms collected within the study area. They distinguish eight different communities: Amphiura filiformis (53 sites), Tellina fabula (40 sites), Goniadella spisula (27 sites), Nucula nitidosa (24 sites) Bathyporeia tellina (20 sites), Macoma balthica (8 sites), benthic organisms of the central North Sea (5 sites) as well as of the Helgoland Depth (4 sites). The methodology to spatially predict the occurrence of these eight benthic communities for the entire study area is summarised in Fig. 2. The CART-calculations were performed with the SPSS-module 'Answer Tree.'

At first, all geostatistically estimated abiotic raster data and the bathymetry map were intersected with the punctual data on benthic communities, resulting in a table build up of 182 rows and 24 columns representing $X$-/Y-coordinates, benthic communities as well as the 20 abiotic parameters listed in Table 1 and the bathymetry. By defining the benthic communities as the target variable and the abiotic parameters as the predictor variables a decision tree was calculated by applying CART. The tree was grown in a way that the minimum number of cases per endnode did not exceed four. This corresponds to the number of sites belonging to the smallest benthic community, here the community "Helgoland Depth" $(n=4)$. Additionally the binary splitting was not continued when the improvement of homogeneity lay below 0.001 . The resulting tree was pruned back so that each of the resulting endnodes at best was dominated by one of the eight communities. Since the decision tree corresponds to a hierarchically ordered set of decision rules these were written into an SQLstatement and applied on the raster data available for the entire study area. In this way a prediction map
Fig. 2 Predictive benthic habitat mapping by CART

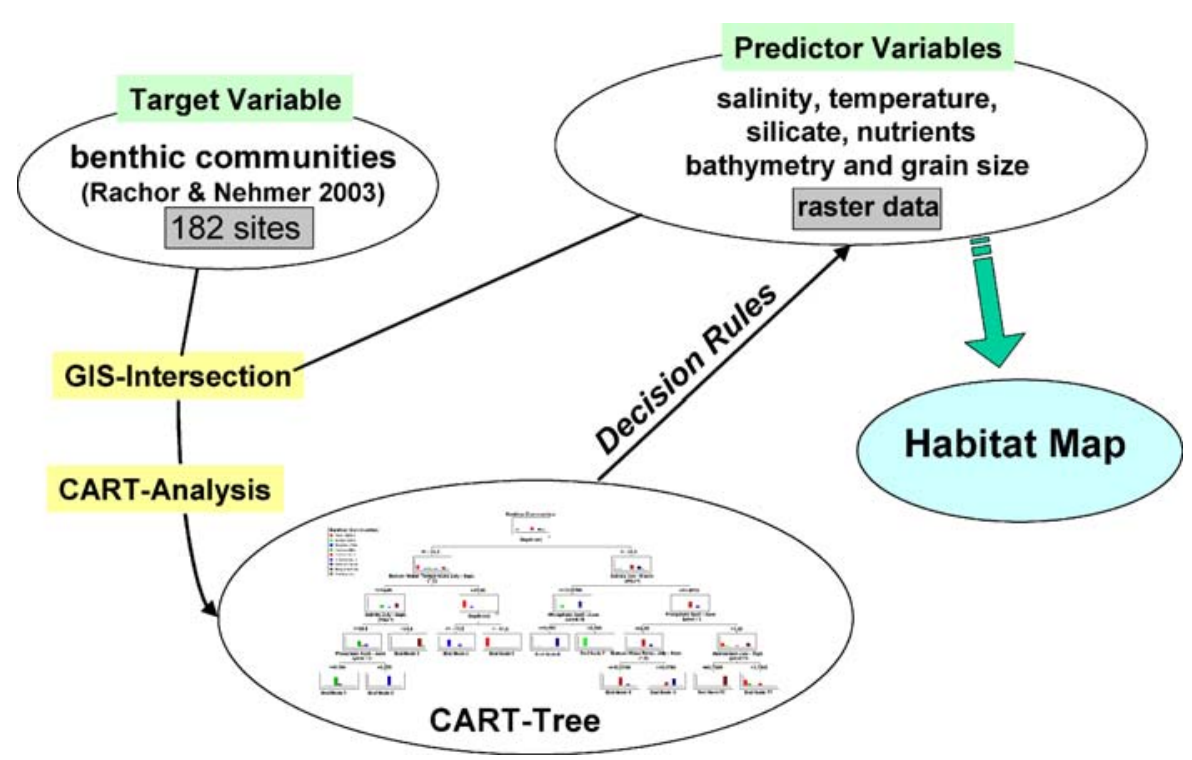


was generated with as many benthic habitat classes as there were endnodes in the underlying decision tree. Finally, the benthic prediction map was intersected with the predictor variables to statistically describe all habitat classes with respect to the abiotic conditions.

The CART analysis resulted in a decision tree grown in nine binary splits leading to 10 endnodes or classes, respectively. Figure 3 depicts the nodes of the decision tree in terms of histograms where each bar represents one of eight communities. The first binary split that subdivides the root node into two subnodes that contain 80 (Node 21 in Fig. 4) and 102 (Node 22 in Fig. 4) sites, respectively, is due to the bottom water temperature in the months between July and September. By example of the two marked benthic communities A. filiformis and N. nitidosa it can be observed that they increase in their percentage in one of the subnodes (A. filiformis from $29.1 \%$ (root node) to $63.8 \%$ (node 21 ) and $N$. nitidosa from $13.2 \%$ (root node) to $22.6 \%$ (node 22 ). By following the dendrogram from up to down it can be observed that the portion of each benthic communities increases stepwise leading to nine endnodes in which one of the eight communities is dominant (portion $>75 \%$ ). Each community is represented once except for Goniadella spisula that can be found in endnode $33(93 \%)$ and endnode $36(100 \%)$. Endnode 32, consisting of 10 sites, is evenly represented by five communities. The nine binary splits that recursively partition the 182 sites were chosen according to six predictor variables: bottom water temperature $\left[{ }^{\circ} \mathrm{C}\right]$ July-September (once) and October-December (once), bottom water salinity [PSU] July-September (twice), bottom water ammonium $[\mu \mathrm{mol} / \mathrm{l}]$ July-September, water depth [m] (once) as well particle size group $0-20 \mu[\mathrm{g} / \mathrm{kg}]$ (three times).

The quality of the decision tree to predict the eight benthic communities may be described with the aid of the misclassification matrix depicted in Table 4. Here for each community both successfully classified and misclassified cases are listed. It can be seen that, except for $M$. balthica, all other communities are successfully classified to at least $75 \%$. The smallest misclassification rate can be found for $N$. nitidosa (12.5\%) as well as A. filiformis (7.55\%). By dividing all misclassified cases through the total number of cases an overall misclassification rate or risk estimate of merely $16 \%$ can be calculated.

Since each endnode is determined by decision rules, the tree can be applied to predict benthic communities at sites where such information is not available. By doing this for all geostatistically estimated raster cells within the EEZ and its bordering areas, a predictive habitat map was calculated with respect to the occurrence of benthic communities derived by Rachor and Nehmer (2003). This map is

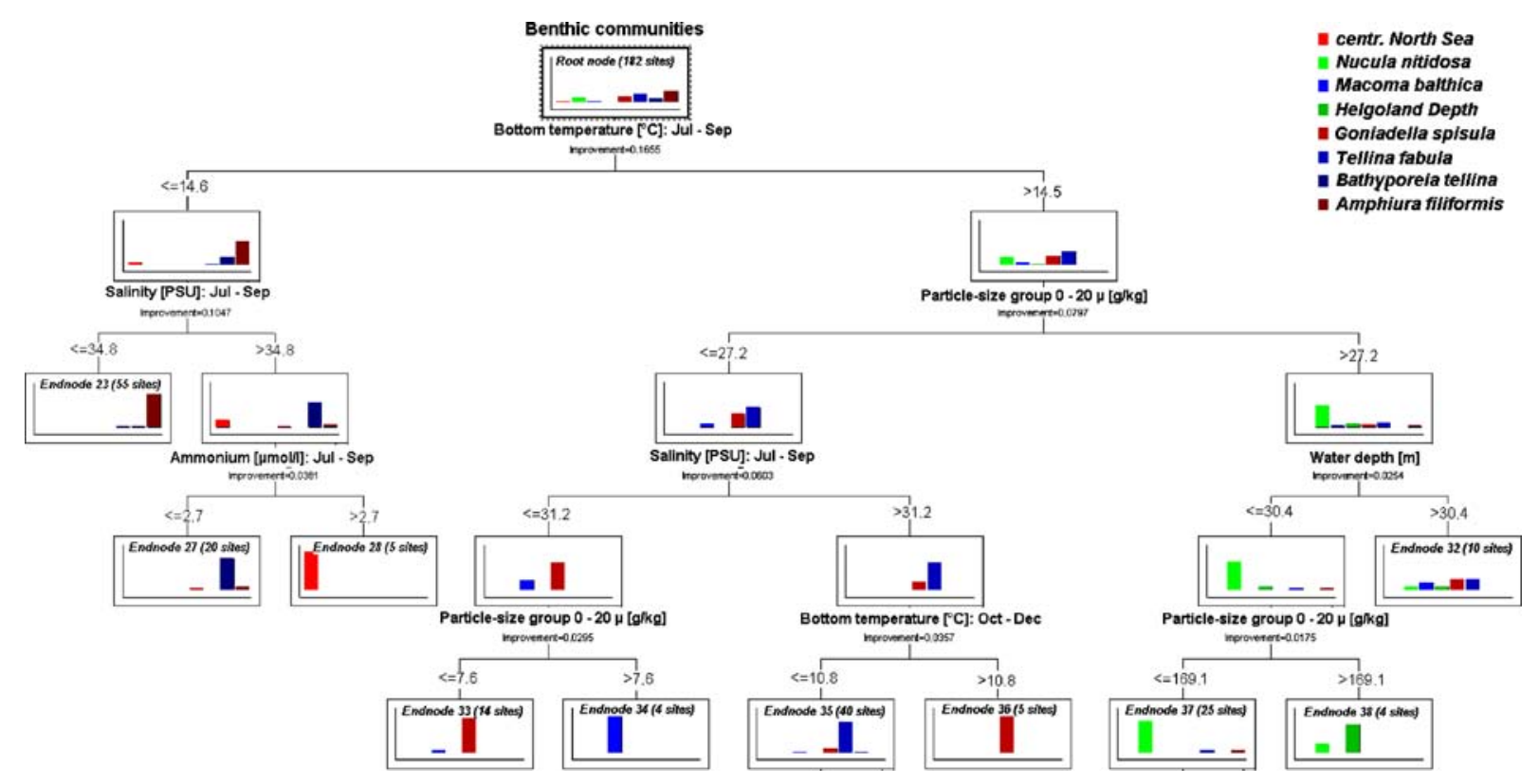

Fig. 3 Predictive benthic habitat classification tree for the EEZ of the North Sea 


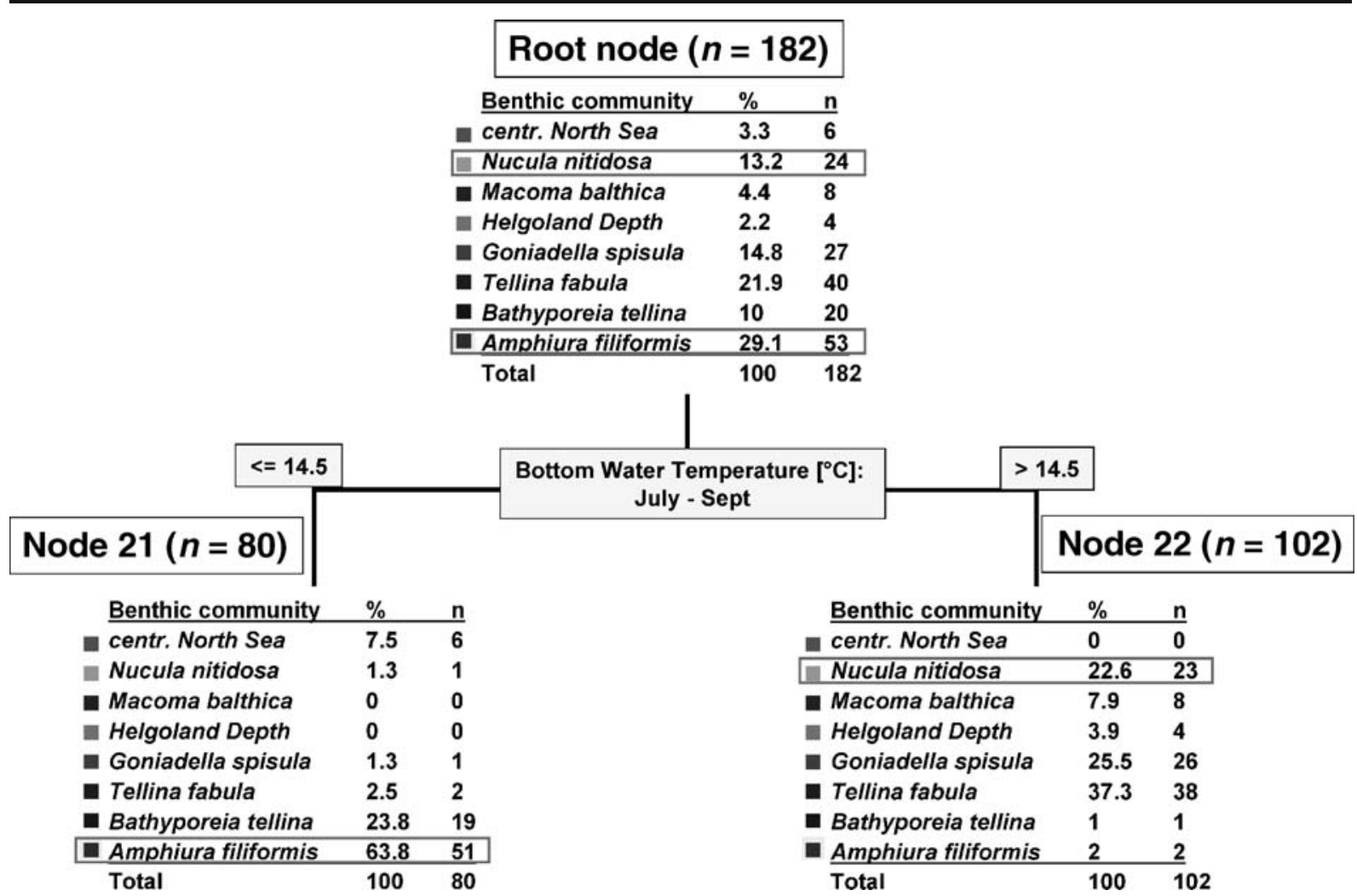

Fig. 4 First split of the predictive benthic habitat classification tree for the EEZ of the North Sea

depicted in Fig. 5. Each of the 10 endnodes described in Fig. 3 corresponds to one of the 10 spatial units illustrated in Fig. 5. Each of these spatial units may therefore be described with respect to the possibility of the occurrence of one of the eight communities. This possibility of the occurrence of each community can be derived from its percentage in the corresponding endnode.

\section{Discussion}

With regard to its scientific plausibility the decision tree depicted in Fig. 4 mirrors existing knowledge about potential classification schemes for benthic habitats in the North Sea. Peterson (1914), Remane (1940), Thorson (1957), Jones (1950), Duineveld et al. (1991), Kuenitzert et al. (1992), Salzwedel et al. (1985), Heip and Craeymeersch (1995) and Rachor and Nehmer (2003) refer to the bathymetry and the sediment conditions to be important for the density and distribution of benthic organisms or the composition of benthic habitat complexes. This corresponds to the results of the CART-analysis: of nine binary splits water depth and sediment (in terms of the particle size group 0-20 $\mu$ ) were chosen four times in the CART-tree that was calculated for the occurrence of benthic communities in the study area. Jones (1950), Glémarec (1973) and Kuenitzert et al. (1992) furthermore claim temperature to be responsible for the spatial distribution of faunistic communities. Jennings et al. (2001) found the temperature conditions and the water depth to be the most important environmental factors able to discriminate the grouping of sites according to chosen attached and free living epibenthic species. With regard to the classification system derived by the CART-analysis the temperature conditions near the sea floor were taken twice to be the most important predictors for the benthic communities. Further, according to OSPAR (2000) changes of the benthic populations among other things correlates with changes of the degree of eutrophication which might be the reason why the bottom water ammonium concentration was chosen as a predictor in the CART analyses presented in this article. The meaning of bottom water salinity (chosen 
Table 4 Misclassification matrix for the prediction of the eight benthic communities

\begin{tabular}{|c|c|c|c|c|c|c|c|c|c|}
\hline & & \multicolumn{8}{|c|}{ Category } \\
\hline & & $\mathrm{cNS}$ & $\mathrm{NN}$ & MB & $\mathrm{HD}$ & GS & $\mathrm{TF}$ & BT & $\mathrm{AF}$ \\
\hline \multirow[t]{8}{*}{ Predicted } & centr. North Sea (cNS) & 5 & 0 & 0 & 0 & 0 & 0 & 0 & 0 \\
\hline & Nucula Nitidosa (NN) & 0 & 21 & 0 & 0 & 0 & 2 & 0 & 2 \\
\hline & Macoma Balthica (MB) & 0 & 0 & 4 & 0 & 0 & 0 & 0 & 0 \\
\hline & Helgoland Depth (HD) & 0 & 1 & 0 & 3 & 0 & 0 & 0 & 0 \\
\hline & Goniadella Spisula (GS) & 0 & 1 & 3 & 1 & 21 & 3 & 0 & 0 \\
\hline & Tellina Fabula (TF) & 0 & 0 & 1 & 0 & 5 & 33 & 1 & 0 \\
\hline & Bathyporeia Tellina (BT) & 0 & 0 & 0 & 0 & 1 & 0 & 17 & 2 \\
\hline & Amphiura Filiformis (AF) & 1 & 1 & 0 & 0 & 0 & 2 & 2 & 49 \\
\hline \multicolumn{2}{|l|}{ Total } & 6 & 24 & 8 & 4 & 27 & 40 & 20 & 53 \\
\hline \multicolumn{2}{|c|}{ Misclassified } & 1 & 3 & 4 & 1 & 6 & 7 & 3 & 4 \\
\hline \multicolumn{2}{|c|}{ Misclassified \% } & 16.67 & 12.50 & 50.00 & 25.00 & 22.22 & 17.50 & 15.00 & 7.55 \\
\hline
\end{tabular}

as a predictor twice) for the abundance of epibenthic organisms was proven in an investigation made by Callaway et al. (2002).

As was carried out in "Data basis and preparation" section the first methodological step to calculate a predictive benthic habitat map consisted in the geostatistical analysis of abiotic measurement data that was aggregated according to four monthly time intervals within the year aggregated over a 6 year period from 1995 to 2000. Such aggregation was done with regard to two reasons: (1) to guarantee a sufficient coverage of measurement values across the study area and (2) to cover a sufficiently long time period to characterise the abiotic conditions near the

Habitat

3030 Amphiura filiformis (89 \%)

Bathyporeia tellina (85\%), Amphiura filiformis (10\%) central North Sea (100\%)

Tellina fabula (83\%), Goniadella spisula (12,5\%)

ZiJ Goniadella spisula (100\%)

Goniadella spisula (93\%)

…… Helgoland Depth (75\%), Nucula nitidosa (25\%)

Macoma balthica $(100 \%)$

$\$ \mathbb{N}$ Nucula nitidosa (84\%)

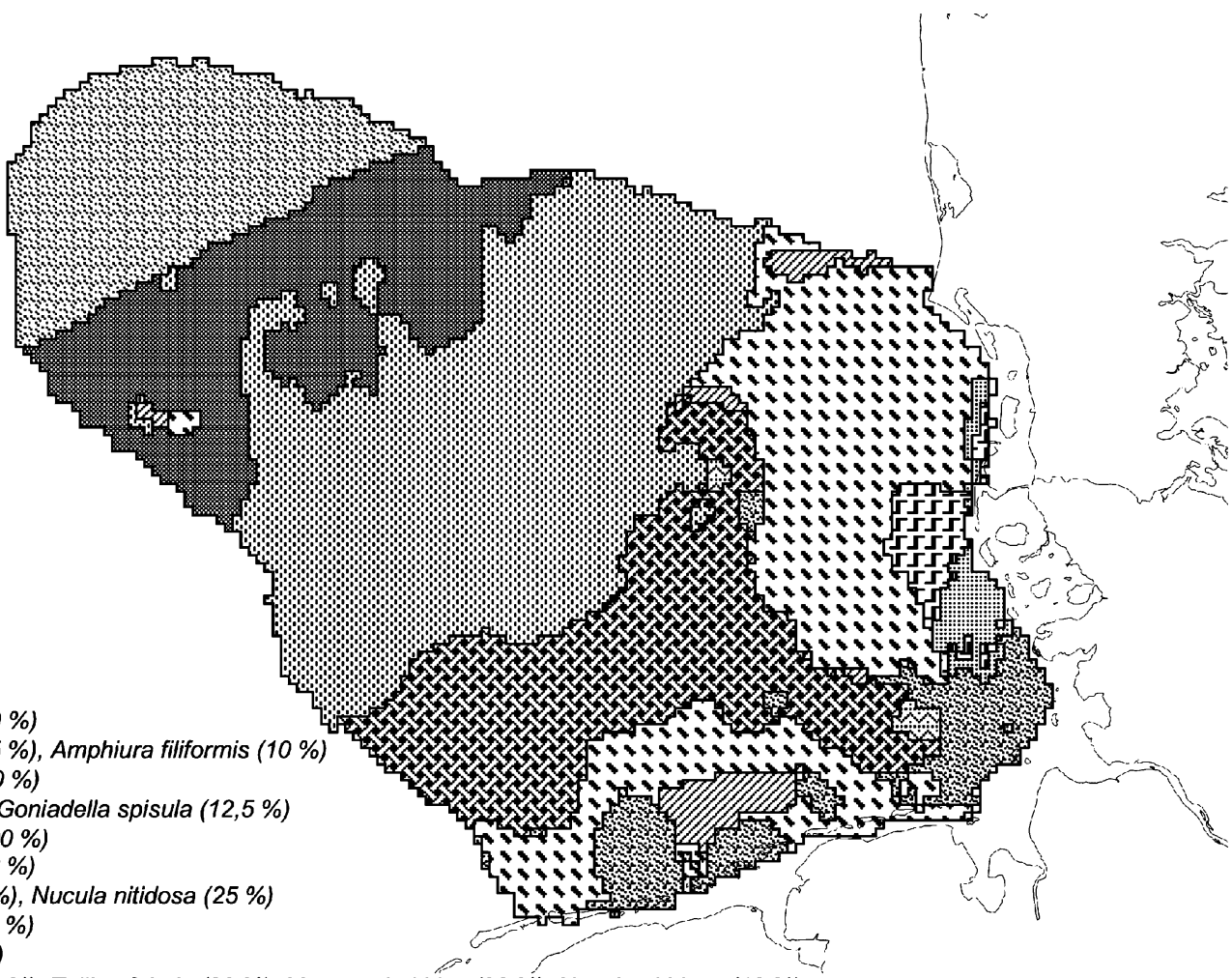

Goniadella spisula (30\%), Tellina fabula (30\%), Macoma balthica (20\%), Nucula nitidosa (10\%)

Fig. 5 Predictive benthic habitat map for the German EEZ of the North Sea and bordering area 
Table 5 Variation of measurement values between 1995 and 2000 for four monthly time intervals

\begin{tabular}{|c|c|c|c|c|c|}
\hline \multirow[t]{2}{*}{ Parameter } & \multirow[t]{2}{*}{ Time interval } & \multirow[t]{2}{*}{ Number of sites } & \multicolumn{2}{|c|}{ Values/site } & \multirow{2}{*}{$\begin{array}{l}\text { Mean coefficient } \\
\text { of variation }(\%)\end{array}$} \\
\hline & & & $\min$ & $\overline{\max }$ & \\
\hline \multirow[t]{2}{*}{ Ammonium } & January-March & 45 & 2 & 4 & 39.5 \\
\hline & July-September & 34 & 2 & 3 & 38.7 \\
\hline \multirow[t]{2}{*}{ Nitrate } & January-March & 30 & 2 & 3 & 29.2 \\
\hline & July-September & 58 & 2 & 3 & 36.9 \\
\hline \multirow[t]{2}{*}{ Phosphate } & January-March & 53 & 2 & 7 & 25.9 \\
\hline & July-September & 60 & 2 & 3 & 33.3 \\
\hline \multirow[t]{4}{*}{ Salinity } & January-March & 233 & 2 & 32 & 1.14 \\
\hline & April-June & 353 & 2 & 35 & 0.48 \\
\hline & July-September & 221 & 2 & 21 & 0.70 \\
\hline & October-December & 66 & 2 & 17 & 1.03 \\
\hline \multirow[t]{2}{*}{ Silicate } & January-March & 61 & 2 & 7 & 23.0 \\
\hline & July-September & 44 & 2 & 4 & 43.4 \\
\hline \multirow[t]{4}{*}{ Temperature } & January-March & 260 & 2 & 32 & 14.0 \\
\hline & April-June & 331 & 2 & 35 & 4.60 \\
\hline & July-September & 241 & 2 & 21 & 3.26 \\
\hline & October-December & 66 & 2 & 17 & 9.79 \\
\hline
\end{tabular}

sea floor (Kröncke and Bergfeld (2001) suggest that such a time period should at least cover 3 years). To account for temporal variances of the abiotic parameters coefficients of variation were calculated at places were sampling was performed more than once between 1995 and 2000 (Table 5). Considering the predictor variables chosen to calculate the decision tree depicted in Fig. 4 only bottom water ammonium between July and September shows high mean coefficients of variation $(38.7 \%$ from multiple measurements at 34 stations). The bottom water temperature between July and September shows mean coefficients of $3.26 \%$ calculated from 241 measurement stations where samples were taken up to 21 times within the 6 year period. For the same parameter measured between October and December the mean coefficient is $9.79 \%$ (number of measurement sites $=66$ ). The bottom water salinity values seem to be stable throughout the study period. All mean coefficients amount to less than $2 \%$.

In further analyses, the benthic habitat map presented in this study has to be checked in terms of a sensitivity analysis regarding other methodological alternatives. The classification technique CART is one of the most frequently applied decision tree algorithm although other such methods are available. In further studies the CART results should therefore be compared with other habitat maps calculated with the aid of decision tree algorithms like CHAID (Chi-squared Automatic Interaction Detector) or QUEST (Quick, Unbiased, Efficient Statistical Tree). Provided that predictive habitat maps are to be calculated for the abundance of chosen benthic indicator organisms multivariate regression could be applied as well. Furthermore, more emphasis should be laid on the calculation of raster maps by means of other geostatistical methods. In this study a univariate kriging method (ordinary kriging) was used to produce valid surface estimations. In future investigations bi- and multivariate kriging methods should be applied. Such methods account for secondary information that can be implemented in the estimation process. This might be especially commendable for the calculation of a sediment map for the sea floor of the North Sea since the sediment distribution is one of the most important predictors to characterise the sea floor in terms of its biological properties. Existing measurement data on grain size ranges should be combined with available sedimentological maps to first calculate grain size maps and then to aggregate such maps with the aid of existing sedimentological classification systems to an overall sediment map of the North Sea. Attempts to achieve this goal were started within the MarGISproject using detailed and high resolution sediment data generated and made available by the BSH (Federal Maritime and Hydrographical Office), GEUS 
(Geological Survey of Denmark and Greenland) as well as by other international and national institutes and authorities (Jerosch et al. 2005).

Acknowledgements This is publication no. GEOTECH -187 of the programme Geotechnologien of BMBF and DFG; Grant 03F0370B.

\section{References}

Arentze, T., \& Timmermans, H. (2005). An analysis of context and constraints-dependent shopping behaviour using qualitative decision principles. Urban Studies, 42(3), 435-448.

Breiman, L., Freidman, J. H., Olshen, R. A., \& Stone, C. J. (1984). Classification and regression trees. Wadsworth.

Callaway, R., Alsvåg, J., De Boois, I., Cotter, J., Ford, A., Hinz, H., et al. (2002). Diversity and community structure of epibenthic invertebrates and fish in the North Sea. ICES Journal of Marine Science, 59, 1199-1214.

Chihi, H., Galli, A., Ravenne, C., Tesson, M., \& De Marsily, G. (2000). Estimating the depth of stratigraphic units from marine seismic profiles using nonstationary geostatistics. Natural Resources Research, 9(1), 77-95.

Duineveld, G. C. A., Kuenitzer, A., Niermann, U., De Wilde, P. A. W. J., \& Gray, J. S. (1991). The macrobenthos of the North Sea. Netherlands Journal of Sea Research, 28(1-2), 53-65.

Glémarec, M. (1973). The benthic communities of the European North Atlantic shelf. Oceanography and Marine Biology: An Annual Review, 11, 263-289.

Heip, C., \& Craeymeersch, J. A. (1995). Benthic community structures in the North Sea. Helgoland Marine Research, 49, 313-328.

Huetmann, F., \& Diamond, A. W. (2001). Seabird colony locations and environmental determination of seabird distribution: A spatially explicit breeding seabird model for the Northwest Atlantic. Ecological Modelling, 141(1), 261-298.

Hughes, R. M. (1997). Use of ecoregions in biological monitoring. In S. L. Loeb \& A. Spacie (Eds.), Biological monitoring of aquatic systems (pp. 125-151). Boca Raton, FL.

ICES (2005). Report of the Working Group on Habitat Mapping (WGMHM). Bremerhaven, Germany: ICES, C. M. 2005/E:05, 87.

Jennings, S., Lancaster, J., Woolmer, A., \& Cotter, J. (2001). Distribution, diversity and abundance of epibenthic fauna in the North Sea. Journal of the Marine Biological Association of the United Kingdom, 79, 385-399.

Jerosch, K., Pesch, R., \& Schlüter, M. (2006). Spatial analysis of marine categorical information using indicator kriging applied to georeferenced video mosaics of the deep-sea Håkon Mosby Mud Volcano. Ecological Informatics, 1(4), 391-406. doi:10.1016/j.ecoinf.2006.05.003.

Jerosch, K., Schlüter, M., Pesch, R., Schröder, W., Köberle, A., \& Vetter, L. (2005). MarGIS Marine Geo-InformationSystem for visualisation and typology of marine geodata. In Conference Proceedings EnviroInfo, (pp. 165-174).
Johnston, K., Ver Hoef, V. M., Krivoruchko, K., \& Lucas, N. (2001). Using ArcGIS geostatistical analyst. Tulsa, USA: ESRI Selbstverlag.

Jones, N. S. (1950). Marine bottom communities. Biological Reviews, 25, 283-313.

Kingston, P. F., \& Rachor, E. (1982). North Sea level bottom communities. ICES, C.M.1982/L:41, 20.

Krige, D. G. (1951). A statistical approach to some basic mine evaluation problems on the Witwatersrand. Journal of the Chemical and Metallurgical Society of South Africa, 52(6), 119-139.

Kröncke, I., \& Bergfeld, C. (2001). Synthesis and new conception of North Sea research (SYCON), working group 10: Review of the current knowledge on North Sea benthos. Berichte ZMK, Reihe Z, 12, 138.

Kuenitzert, A., Basford, D., Craeymeersch, J. A., Dewarumez, J. M., Dorjes, J., Duineveld, G. C. A., et al. (1992). The benthic infauna of the North Sea: Species distribution and assemblages. ICES Journal of Marine Science, 49(2), 127-143.

Lawrence, R., \& Labus, M. (2003). Early detection of DouglasFir beetle infestation with subcanopy resolution hyperspectral imagery. Western Journal of Applied Forestry, 18(3), 202-206.

Lourie, S. A., \& Vincent, A. C. J. (2004). Using biogeography to help set priorities in marine conservation. Conservation Biology, 18(4), 1004-1020.

Matheron, G. (1965). Les variables régionalisées et leur estimation. Paris: Masson.

Matheron, G. (1971). The theory of regionalized variables and its application. Fontainebleau.

Norcross, B. L., Blanchard, A., \& Holladay, B. A. (1999). Comparison of models for defining nearshore flatfish nursery areas in Alaskan waters. Fishery and Oceanography, 8(1), 50-67.

OSPAR Commission (2000). Quality status report 2000: Region II - Greater North Sea. London, U.K.: OSPAR Commission, $136+$ xiii.

Pehlke, H. (2005). Prädiktive Habitatkartierung für die Ausschließliche Wirtschaftszone (AWZ) der Nordsee, Diplomarbeit, Universität Vechta, Institut für Umweltwissenschaften.

Petersen, C. G. J. (1914). Valuation of the sea II. The animal communities on the sea-bottom and their importance for marine zoogeography. Report of the Danish Biological Station, 21, 1-44.

Petitgas, P. (1997). Sole egg distribution in space and time characterised by a geostatistical model and its estimation variance. ICES Journal of Marine Science, J. Conseil., International Council for the Exploration of the Sea, (Bd. 54, pp. 213-225). London: Academic.

Poon, K. F., Wong, R. W. H., Lam, M. H. W., Yeung, H. Y., \& Chiu, T. K. T. (2000). Geostatistical modelling of the spatial distribution of sewage pollution in coastal sediments. Water Research, 34(1), 99-108.

Rachor, E., \& Nehmer, P. (2003). Erfassung und Bewertung ökologisch wertvoller Lebensräume in der Nordsee, Abschlußbericht für das FuE-Vorhaben FKZ 89985310 (Bundesamt für Naturschutz). Bremerhaven: AlfredWegener-Institut für Polar- und Meeresforschung. 
Reiniger, C. (1997). Bioregional planning and ecosystem protection. In G. F. Thompson \& F. Steiner (Eds.), Ecological design and planning (pp. 185-200). New York.

Remane, A. (1940). Einführung in die zoologische Ökologie der Nord- und Ostsee. In Tierwelt der Nord-und Ostsee Ia (p. 238). Leipzig, Germany: Grimpe and Wagler.

Rosenfeld, B., \& Lewis, C. H. (2005). Assessing violence risk in stalking cases: A regression tree. Law and Human Behavior, 29(3), 343-357.

Ryan, W. F. (1995). Forecasting severe ozone episodes in the Baltimore metropolitan area. Atmospheric Environment, 29(17), 2387-2398.

Salzwedel, H., Rachor, E., \& Gerdes, D. (1985). Benthic macrofauna communities in the German Bight. Institut für Meeresforschung in Bremerhaven, 20, 199-267.

Schlüter, M., Rutgers van der Loeff, M. M., Holby, O., \& Kuhn, G. (1998). Silica cycle in surface sediments of the South Atlantic. Deep-Sea Research I, 45, 1085-1109.

Schröder, W., \& Schmidt, G. (2003). Medienübergreifende Umweltbeobachtung in Baden-Württemberg. Ergebnisse eines Modellprojekts. In Landesanstalt für Umweltschutz (Eds.), Medienübergreifende Umweltbeobachtung (pp. 39-60). Karlsruhe: Stand und Perspektiven.

Steinberg, D., \& Colla, P. (1995). CART: Tree-structured nonparametric data analysis. San Diego, CA: Salford Systems.
Stelzenmüller, V. (2005). Möglichkeiten und Grenzen geostatistischer Verfahren in den Fischereiwissenschaften: Analyse räumlicher und zeitlicher Variabilität von Fischpopulationen (p. 128). Doctoral thesis, Carl von Ossietzky Universität Oldenburg.

Swan, G. E., Javitz, H. S., Jack, L. M., Curry, S. J., \& McAfee, T. (2004). Heterogeneity in 12-month outcome among female and male smokers. Addiction, 99(2), 237-250.

Thorson, G. E. (1957). Bottom communities (sublittoral or shallow shelf). Geol. Soc. Am. Mem., 67(1), 461-534.

Thuiller, W. (2003). BIOMOD - Optimizing predictions of species distributions and projecting potential future shifts under global change. Global Change Biology, 9(10), 1353-1362.

Walmsley, J. L., Barthelmie, R. J., \& Burrows, W. R. (2001). The statistical prediction of offshore winds from landbased data for wind-energy applications. Bound-Lay Meteorology, 101(3), 409-433.

Webster, R., \& Oliver, M. (2000). Geostatistics for environmental scientists (p. 272). Wiley.

Yisehac, Y., \& Webb, P. (1999). Classification and regression trees, cart: A user manual for identifying indicators of vulnerability to famine and chronic food insecurity. International Food Policy Research Institute, Microcomputers in Policy Research, 3. 